\title{
A comparison of green building assessment systems
}

\author{
Thanachon Krajangsri ${ }^{1, *}$ and Jakrapong Pongpeng ${ }^{1}$ \\ ${ }^{1}$ Civil Engineering Department, Faculty of Engineering, King Mongkut's Institute of Technology Ladkrabang, Bangkok, Thailand
}

\begin{abstract}
Construction is one of industries that have negative impacts on the environment. Relevant organizations both in Thailand and other countries have been trying to minimize these impacts. Developing green building assessment systems is one of efforts in reducing environmental impacts and using natural resources efficiently. Currently, there are many green building assessment systems with different objectives and assessment scopes in some details. This could cause some confusion in selecting the suitable system for the project in accordance with its environmental, social and economical contexts. This study was aimed to compare and provide overview and components of these systems. The comparison results can be used as a guideline for further development of green building assessment systems. It is found that most major green building assessment systems still concern only environmental issues while newly developed systems have included social and economic issues in their criteria. Furthermore, the system which is developed in one environment could not be used with full capabilities in another. This will lead to more research in developing the assessment system that is more comprehensive and adaptable enough to be used effectively in various environment.
\end{abstract}

\section{Introduction}

Realizing environmental impacts from construction activities, relevant organizations in several countries developed building environmental assessment systems, also known as green building assessment systems, in early 1990 s as guidelines for design, construction and performance assessment of green buildings. Leading systems are Building Research Establishment Environmental Assessment Method (BREEAM), developed by The Building Research Establishment Ltd. from the UK; Leadership in Energy and Environmental Design (LEED), developed by U.S. Green Building Council from the United States and Comprehensive Assessment System for Built Environment Efficiency (CASBEE), developed by Japan Greenbuild Council/Japan Sustainable Building Consortium from Japan. These systems are widely used both in their origin countries and abroad. Responding to this growing movement, Thai Green Building Council developed Thai's Rating of Energy and Environmental Sustainability and National Housing Agency developed Ecovillage Criteria in 2012 to encourage sustainable construction practices in Thailand.

With different systems and their different objectives, assessment scopes, building types, users, life cycle assessment, environmental, social and economic issues, hesitation could occur in selecting the best system to be used for the project effectively. Therefore, efforts have been made by academics and relevant organizations in energy and environmental sectors to classify these systems.

For instance, ATHENA Institute [1] classifies building environmental assessment systems into 3 levels, while International Energy Agency [2] classifies them into 5 levels according to their scopes of assessment, such as product comparison tools, life cycle assessment tools and whole building performance assessment tools. Reijnders and van Roekel [3] divided the assessment tools into 2 groups as qualitative tools and quantitative tools. The qualitative tools were based on scores and criteria. The quantitative tools considered life cycle assessment, input and output of material uses and energy consumption [4].

Currently, there are increasing numbers of building environmental assessment systems both local and international. Each system has different objectives and assessment scopes. International systems are used either directly or as guidelines for green building assessment system development in some countries. Haapio and Viitaniemi [5] studied 14 building environmental assessment tools including quantitative, qualitative and life cycle assessment tools to classify them according to their scopes. They were compared within the same level with comparison factors: assessed building types, users of the tools, life cycle phases, database of the tools, forms of assessment results.

* Corresponding author: thanachon $($,hotmail.com 
The research was concluded that:

1) The assessment tools were much different depending on needs and purposes of development. The comparison is therefore very difficult.

2) The tools users were unable to assess reliability of the tools and their results.

3) The tools covered different life cycle depending on guidelines and database used.

4) There should be an examination on factors affecting tools selection of the users.

Forsberg and von Malmborg [4] studied 5 quantitative environmental assessment tools and compared them to present their overviews and current status. Some of these tools are already available and some are under development. The comparison factors are: users of the tools, overall purpose, specific purpose, assessed building types, considered issues, research dimensions, basis of comparison, scope of tools, result presentation.

The research was concluded that:

1) The tools studied were developed from life cycle analysis of buildings and materials used.

2) Life cycle assessment still had difficulties in environmental impact assessment.

3) Selecting scope of the assessment tools was important depending of required results.

4) Development of qualitative environmental assessment tools based on life cycle analysis to be sustainability assessment tools should consider social and economic issues as well.

Ding [6] studied 20 environmental assessment tools to present overviews and analyzed assessment methods used in several countries. Their limitations were examined and would be used as basis for improvement. Analysis results were as follows:

1) Using environmental assessment tools as design tools - The tools were useful when used during design phase but will be more useful if use during predesign phase.

2) Selecting appropriate project - The tools were less useful in selecting the project options than assessing the project design.

3) Financial issues - Financial issues should be considered along with environmental issues.

4) Regional variations - Most assessment tools were developed according to their regional environment. Currently there is no single tool that can be used effectively worldwide.

5) Complexity - Environmental assessment is a complex task. Developing a tool that has complete coverage but still simple enough to use was challenging.

6) Quantitative and qualitative data evaluation - Most quantitative evaluation was performed in comparison with collected data and standards. However environmental issues were mostly qualitative data. Obtaining accurate evaluation results was more complex.

7) Weighting - Weighting should be adjusted on project-by-project basis to reflect development objective.
8) Measurement scales - Measurement scales use a scoring system but there was no common basis in determining the score level of each assessment criterion.

With these limitations, there should be a development of assessment tool that could evaluate data in various dimensions. Since construction was an activity involving many complex decisions in environmental, social and economic issues. Developing sustainable indexes was an approach to address multiple criteria in decision-makings of the project. Reijinders and van Roekel [3] studied comprehensiveness and adequacy of environmental building improvement tools. The tools were divided into 2 main groups:

1) Requirement type instruments - Requirement type instruments of the public and private sectors currently had inadequate coverage on environmental issues. They tend to focus on energy and water consumption.

2) Guidance type instruments - Five guidance type instruments studied had more coverage on environmental issues.

However, from literature review it is found that there are few researches comparing components of leading green building assessment systems, which could give the readers more understanding and could be used as guidelines for further system development and improvement on a whole building. This study was aimed to compare green building assessment systems which could be used on a whole building. Six systems were selected for comparison to present their principles and main components. This comparison was expected to assist stakeholders in choosing the best system for the design and construction of green projects effectively in accordance with their environmental, social and economic conditions. It could also be used as a guideline in developing and improving the local green building assessment system.

\section{Methodology}

This research used a qualitative method by examining components of green building assessment systems obtained from previous research works [3-6] and websites of relevant organizations (i.e, manuals of green building assessment systems). Then, the data were verified with data triangulation method by consulting experts and practioners in this area whether the obtained contents are accurate. By examining the different sources of data, the result of data triangulation test showed that all the data from the three different sources (manuals of green building assessment systems, experts, and practitioners) were consistent, which verified the obtained data. After that, the verified data were analyzed with component analysis to compare contextual and methodological aspects. The processes are as follows:

1) Determining framework in selecting systems: For this study, ATHENA Institute classification of green building assessment tools were used as follows:

- Level 1: Product comparison tools and information sources 
- Level 2: Whole building design or decision support tools

- Level 3: Whole building assessment frameworks or systems

The qualitative tools in Level 3 were tools were selected for this study according to Reijnders and van Roekel [3] concepts.

2) Selecting tools: Level 3 tools that could be used as whole building design and construction guidelines and assessment tools were selected.

3) Determining comparison aspects: From the assessment framework for environmental analysis proposed by Baumann and Cowell [7] as used by Forsberg and Malmborg [4] in their study covering contextual and methodological aspects were selected and improved for this study as follows:

Contextual Aspects

- Assessment system developers

- Assessment system users

- Assessment system categories

- Assessment building types

- Assessment system scopes

Methodological Aspects

- Assessment dimensions

- Main assessment criteria

- Assessment result ratings

4) Analyzing information: The related information and aspects were gathered and listed in comparison tables.

5) Summarizing the study.

\section{Results}

Green building assessment systems included in this study are used locally and internationally. BCA Green Mark, BEAM, and TREES are used at locally, mostly in Asian countries. BREEAM, CASBEE and LEED are used internationally as direct implements and guidelines for development of other systems. Results from research in their websites covering contextual and methodological aspects for comparison are shown in Tables 1 .

\section{Summary}

From the study, it is found that green building concept has been practiced for more than 20 years to mitigate environmental problems from construction activities. The concept should be implemented in the project as early as possible, from planning to design, construction and operation phases to maximize its benefits. Green building assessment systems in this study have similar main assessment criteria, such as site, energy efficiency, water efficiency and indoor environmental quality. They are the core concepts of every system. The assessment procedures, users and types of building are also practically similar.

However, comparing these systems to determine which one is better is still difficult because their objectives, contextual and methodological contexts are different in details. The system that is developed to perform most effectively in one environment might not be as effective in another; due to environmental, social and economic differences.

Apparently, LEED is the most widely-used system in Thailand due to its popularity, coverage, proven environmental benefits and added marketability for the certified project. Selecting the right system for the project is quite complicated if the user starts to consider social and economic benefits in addition to environmental in his local condition. Currently, there is no single system that can be used effectively to assess sustainability of construction in all environmental, social and economic conditions. Further study is recommended to develop the system that is comprehensive and adaptable enough to be used with full capability in various environment as a solid guideline for sustainable construction.

\section{References}

1. Athena Sustainable Materials Institute. www.athenasmi.org

2. International Energy Agency, www.iea.org

3. L. Reijnders, A. van Roekel, Comprehensiveness and Adequacy of Tools for the Environmental Improvement of Buildings, J. Cleaner Prod. Elsevier, 7 (1999)

4. A. Forsberg, F. van Malmborg, Tools for Environmental Assessment of the Built Environment, Build. Environ. Elsevier, 39 (2004)

5. A. Haapio, P. Viitaniemi, A Critical Review of Building Environmental Assessment Tools, Environ. Impact Assess. Rev. Elsevier, 28 (2008)

6. G.K.C. Ding, Sustainable Construction - The Role of Environmental Assessment Tools, J. Environ, Manage. Elsevier, 86 (2007)

7. H. Baumann, S. Cowell, An Evaluative Framework for Conceptual and Analytical Approaches Used in Environment Management, Greener Management International, 26 (1999)

8. Building and Construction Authority, Singapore, www.bca.gov.sg

9. BEAM Society, Hong Kong, www.beamsociety.org.hk

10. BRE Global, UK, www.breeam.org

11. Japan GreenBuild Council (JaGBC)/Japan Sustainable Building Consortium (JSBC), Japan, www.ibec.or.jp

12. U.S. Green Building Council, USA, www.usgbc.org

13. Thai's Rating of Energy and Environmental Sustainability for New Construction and Major Renovation and Core and Shell Building, www.tgbi.or.th 


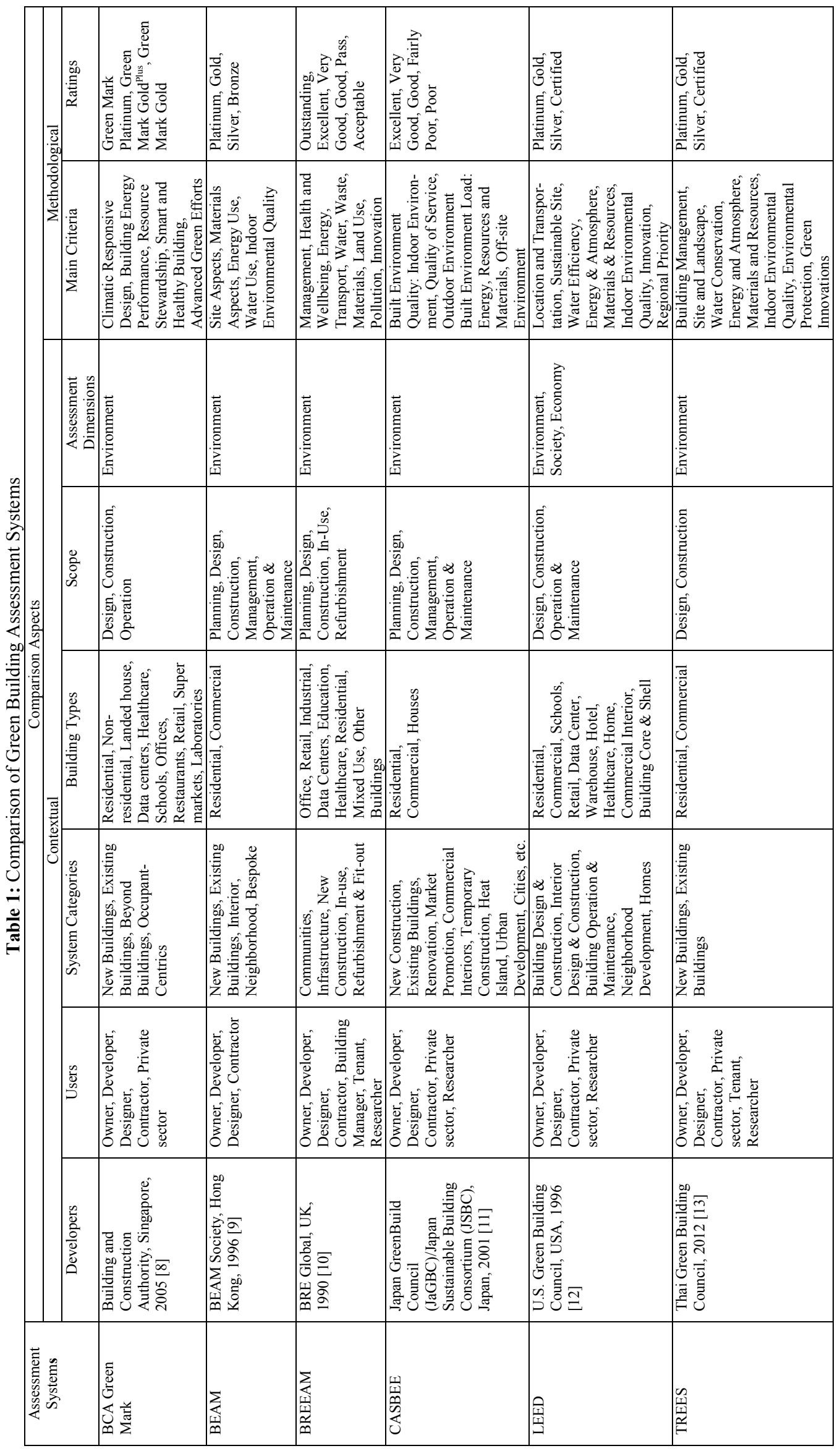

